\title{
Denosumab for Treatment of a Recurrent Cervical Giant-Cell Tumor
}

\author{
Daisuke Kajiwara ${ }^{1,2}$, Hiroto Kamoda ${ }^{1}$, Tsukasa Yonemoto ${ }^{1}$, Shintaro Iwata ${ }^{1}$, Takeshi Ishii ${ }^{1}$, \\ Toshinori Tsukanishi ${ }^{1,3}$, Seiji Ohtori ${ }^{2}$, Masashi Yamazaki ${ }^{3}$, Akihiko Okawa ${ }^{4}$ \\ ${ }^{1}$ Department of Orthopedic Surgery, Chiba Cancer Center, Chiba, Japan \\ ${ }^{2}$ Department of Orthopedic Surgery, Chiba University, Chiba, Japan \\ ${ }^{3}$ Department of Orthopedic Surgery, Tsukuba University, Ibaraki, Japan \\ ${ }^{4}$ Department of Orthopedic Surgery, National Hospital Organization Chiba Medical Center, Chiba, Japan
}

\begin{abstract}
A 43-year-old male patient with C5 giant cell tumor (GCT) underwent tumor resection and anterior bone fusion of C4-C6. The tumor recurred locally 9 months after surgery with the patient complaining of neck and shoulder pain similar to his preoperative symptoms. Denosumab was administered and his pain disappeared after a two-month administration, with a sclerotic rim formation seen at the tumor site on computed tomography. He has been followed for 18 months with no evidence of tumor recurrence. Complete resection is generally recommended, but is not easy for many patients with cervical GCT because of the existence of neurovascular structures. Some patients suffer from recurrence and treatment becomes more difficult. As such, denosumab may be an efficacious option for treatment of recurrent GCT of the cervical spine, although long-term follow-up is required to monitor for presence or absence of recurrence.
\end{abstract}

Keywords: Cervical vertebrae; Giant cell tumor of bone; Recurrence; Denosumab

\section{Introduction}

Giant cell tumor (GCT) of bone is a primary tumor that commonly occurs in the epiphyses of long bones, and most frequently in the distal end of the femur [1]. GCT seldom occurs in the vertebrae above the sacrum and its occurrence in the cervical spine is rare [2]. GCT of bone is categorized as benign, but it has a tendency to local aggressiveness and with recurrence leading to difficulty in full recovery. We describe a case of recurrent GCT in the cervical spine that was managed using denosumab.

\section{Case Report}

A 43-year-old man presented with a 2-month history of progressive neck pain. Neurological examination results were normal. X-ray imaging and computed tomography (CT) of his cervical spine revealed an osteolytic change in the vertebral body of C5 (Fig. 1). The intervertebral disc space was well preserved. On magnetic resonance imaging, the $\mathrm{C} 5$ vertebral body showed hypointense signals on T1-weighted imaging (T1WI) and hyperintense signals on T2WI (Fig. 2). Signal change was also seen in the anterior tubercle and left transverse foramen, but not in laminae.

Received Nov 24, 2015; Revised Jan 6, 2016; Accepted Jan 11, 2016

Corresponding author: Hiroto Kamoda

Department of Orthopedic Surgery, Chiba Cancer Center, 666-2 Nitona, Chuo-ku, Chiba 260-8717, Japan

Tel: +81-43-264-5431, Fax: +81-43-262-8680, E-mail: kamodahiroto@gmail.com 
A biopsy was taken under general anesthesia, and the tumor was histopathologically confirmed to be a GCT of the bone and was resected via an anterior cervical ap-

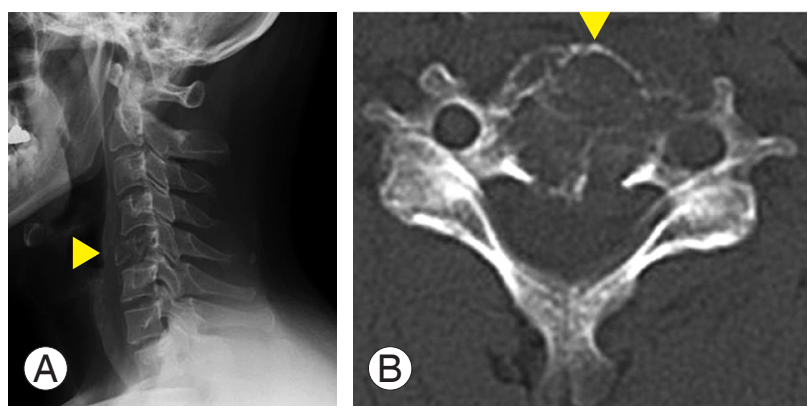

Fig. 1. Imaging findings at the initial visit. (A) X-ray image and (B) computed tomography of the cervical spine revealing the presence of osteolytic change in the C5 vertebral body.

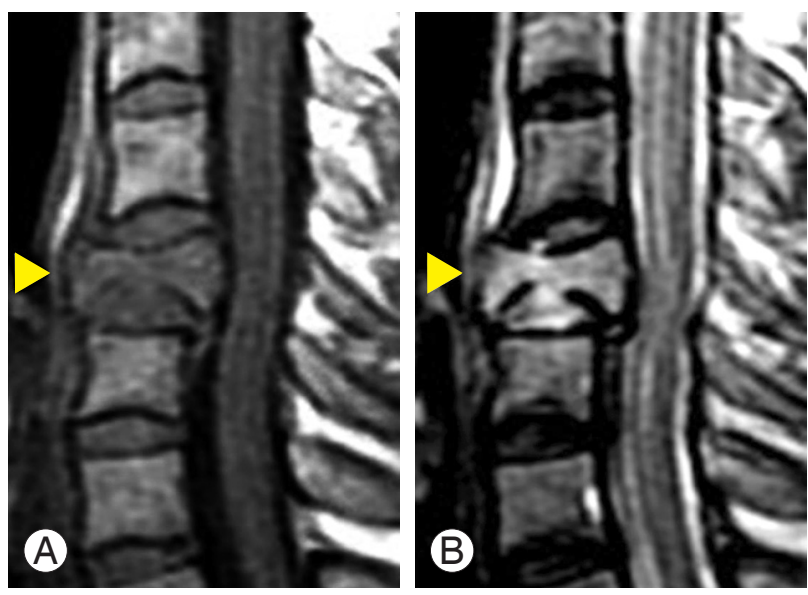

Fig. 2. Preoperative cervical magnetic resonance imaging. C5 vertebral body ( $\boldsymbol{\Delta}$ ) with hypointense signals on (A) T1-weighted imaging (T1WI) and hyperintense signals on (B) T2WI.

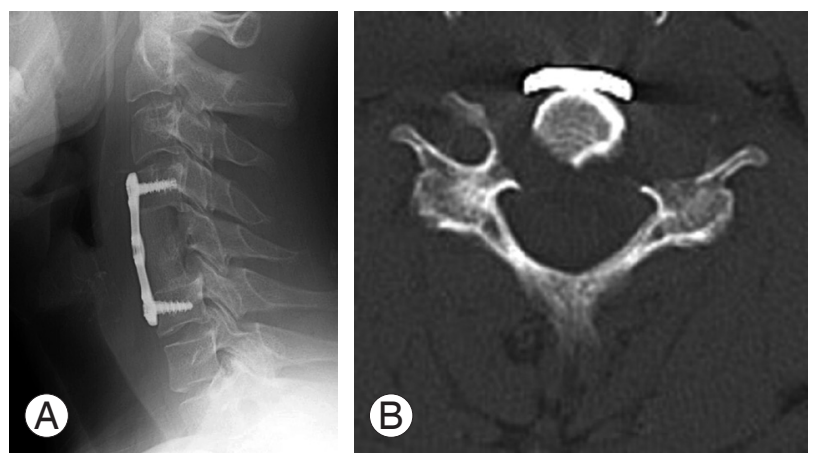

Fig. 3. Imaging findings after surgery. (A) X-ray image showed that C4-C6 fusion was performed using an iliac crest bone graft and anterior cervical plate. (B) Axial computed tomography showed that the vertebral body and the left anterior tubercle of C5 were completely resected. proach. Bilateral vertebral arteries were not involved, and were preserved. After high-speed burring of the tumor margin, C4-C6 fusion was performed with an iliac crest bone graft and anterior cervical plate (Fig. 3). The postoperative course was unremarkable. The patient's neck pain was resolved one week after surgery, and he was discharged from hospital 2 weeks after surgery with normal neurological examination results.

Approximately 9 months later, the patient had neck pain similar to his preoperative symptoms, and without any neurological deficit. CT of the cervical spine showed an osteolytic lesion of the bilateral articular processes, and we diagnosed it as recurrent GCT (Fig. 4). The patient did not wish to undergo the second surgery that we considered. We offered denosumab treatment, which he accepted. Denosumab (120 mg; Amgen, Thousand Oaks, CA, USA) was administered subcutaneously on days 1,8 , 15 , and 29 , and subsequently every 4 weeks. A vitamin D and a calcium supplement were taken orally to avoid hypocalcemia. No major complications were associated with denosumab administration. Two months after beginning treatment, significant bone formation was confirmed at the site of recurrence (Fig. 5). His symptoms at the time of recurrence gradually resolved. Eighteen months after beginning treatment, formed bone was maintained, and no evidence of recurrence was seen on CT imaging (Fig. 6). He continued to tolerate the treatment without any symptoms suggestive of recurrence.

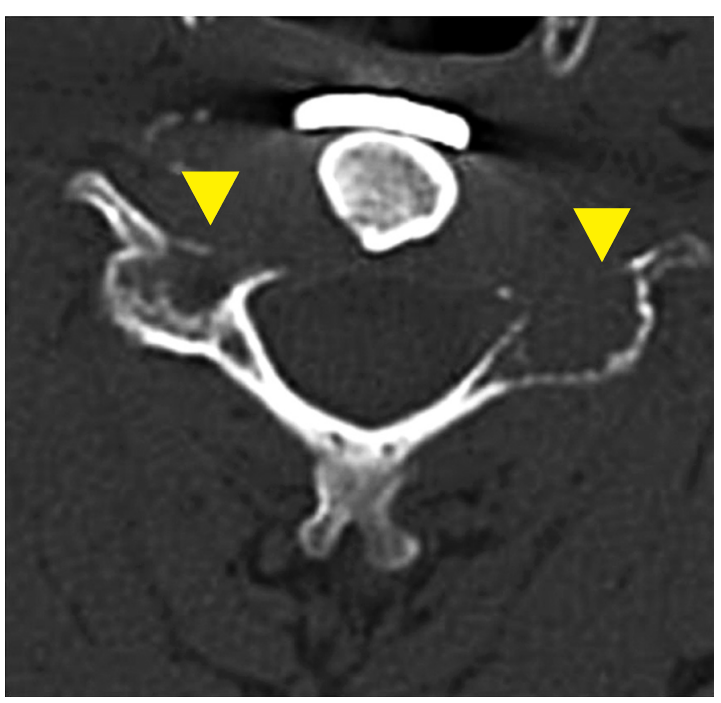

Fig. 4. Computed tomography at recurrence. Axial computed tomography of the C5 vertebral body showed an osteolytic lesion of the bilateral articular processes $(\mathbf{A})$. 


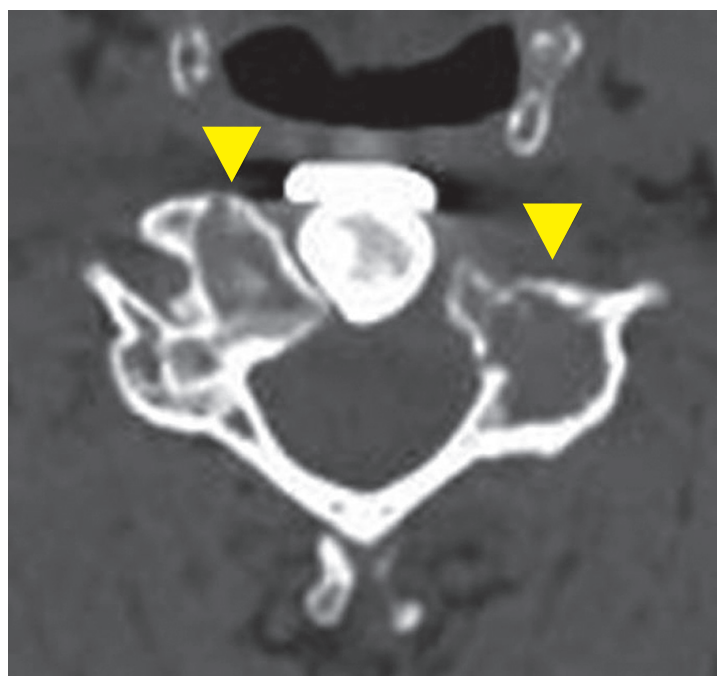

Fig. 5. Computed tomography after initiation of denosumab therapy. Significant bone formation is seen at the area of the tumor recurrence at the $\mathrm{C} 5$ vertebral body $(\boldsymbol{\Lambda})$.

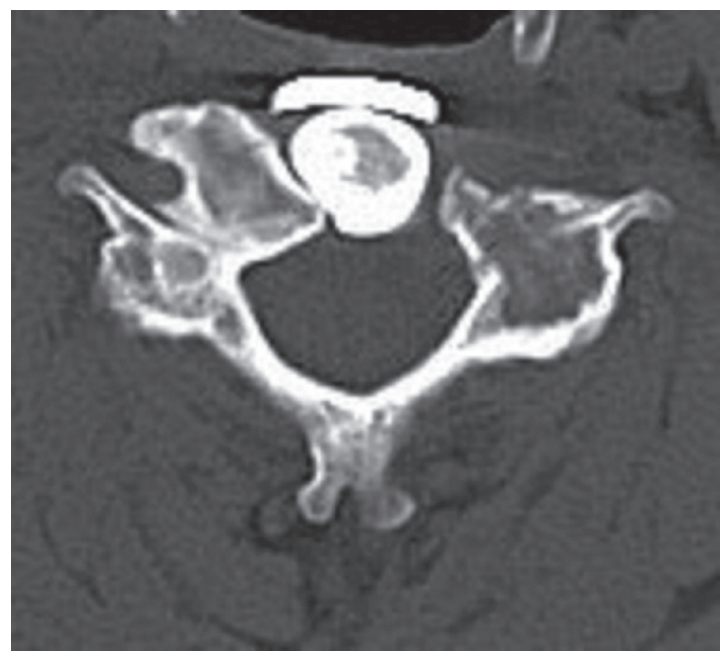

Fig. 6. Computed tomography imaging at the final visit. Bone formation resulting from administration of denosumab was maintained, and local repeat recurrence was not observed.

\section{Discussion}

In this study, we used denosumab to treat a recurrent GCT of the cervical spine and showed that the treatment was effective, both clinically and radiologically, and with no adverse side effects noted. GCTs account for $4 \%-5 \%$ of primary bone tumors and about $20 \%$ of benign bone tumors [3]. The incidence of GCT in the spine above the sacrum is estimated at between $0.1 \%$ and $0.25 \%$ of all bone tumors [4]. GCT may exhibit aggressiveness, often associated with enhanced osteolysis with a soap bubble- like multilocular appearance, and the development of lung metastasis [5].

The GCT consists of osteoclast-like multinucleated giant cells, round monocyte-like cells, and spindle-shaped fibroblast-like stromal cells [6]. Osteoclast-like giant cells express receptor activator of nuclear factor kappa-b (RANK) and fibroblast-like stromal cells express RANKligand (RANKL). The GCT pathogenesis may be the result of an imbalance in the RANK-RANKL pathway [1]. The optimal management of GCTs is complete tumor resection with a wide margin [7]. However, management of patients with cervical GCT is not easy because of its anatomical peculiarity, where complete wide resection is normally difficult to achieve [4]. Several cases of cervical tumor recurrence after subtotal excision have been reported [8-10].

To date, there is no consensus for the treatment of cervical GCT [10]. Because our patient did not wish to undergo additional surgery, we considered other options such as radiation therapy, embolization, or chemotherapy. However, these options are controversial considering their advantages and disadvantages [11-17]. Denosumab, a monoclonal antibody to RANKL, has been used for the treatment of GCT with good results: a phase II study of denosumab demonstrated a tumor response in 30/35 patients [18], and the investigators established the therapeutic potential of denosumab to inhibit progressive bone destruction in unsalvageable GCT. Post-treatment tissue samples from 16 patients showed spindle-shaped celldense stroma were replaced with less cellular stroma in the tumor central area and woven bone transitioned to normal lamellar bone at the peripheral margin of the tumor.

Denosumab was effective for our treatment of recurrent GCT without any side effects. The clinical symptoms disappeared after commencing of the treatment, and cervical $\mathrm{X}$-ray imaging showed bone formation in the area surrounding the relapse, similar to the phase II study findings.

Some adverse effects, such as hypocalcemia (5\%), osteonecrosis of the jaw (1\%), and atypical femoral fractures are associated with denosumab use [19]. Therefore, routine monitoring of calcium levels in the blood is necessary, and calcium and vitamin D supplementation as required. Additionally, regular dental examination is recommended. The incidence of atypical femoral fractures associated with denosumab use remains incompletely understood $[20,21]$. $\mathrm{X}$-ray examination of the femur is recommended if the patient complains of dull pain in the thighs. Furthermore, 
Kobayashi and Setsu [22] reported a case in which sclerosing bands were seen in almost all of the radiographs of the metaphysis after treatment with denosumab. Considering these side effects, long-term administration of denosumab should be avoided.

Currently, however, there is no defined endpoint for use of denosumab as a treatment for GCT [23], and there have been cases of recurrent GCT following the cessation of denosumab therapy $[22,24]$. In light of the previous reports showing that the mean time to recurrence was about two years after surgery $[25,26]$, we think that the 18 -month follow-up period of our case is still insufficient and that it would be appropriate to administer denosumab with careful observation for at least two years after recurrence.

Recently, some GCT cases have been described in which neoadjuvant denosumab therapy before spine surgery achieved good results $[27,28]$. Although we obtained a good result using denosumab after a recurrence of GCT, it is necessary to consider the appropriate timing of administration before and after surgery.

In conclusion, we consider that if possible, complete resection is optimal for recurrent cervical GCT, but that denosumab is an efficacious treatment option as shown in the present case.

\section{Conflict of Interest}

No potential conflict of interest relevant to this article was reported.

\section{References}

1. Dufresne A, Derbel O, Cassier P, Vaz G, Decouvelaere AV, Blay JY. Giant-cell tumor of bone, antiRANKL therapy. Bonekey Rep 2012;1:149.

2. Junming M, Cheng Y, Dong C, et al. Giant cell tumor of the cervical spine: a series of 22 cases and outcomes. Spine (Phila Pa 1976) 2008;33:280-8.

3. Balke M, Henrichs MP, Gosheger G, et al. Giant cell tumors of the axial skeleton. Sarcoma 2012;2012: 410973.

4. Refai D, Dunn GP, Santiago P. Giant cell tumor of the thoracic spine: case report and review of the literature. Surg Neurol 2009;71:228-33.

5. Gamberi G, Serra M, Ragazzini P, et al. Identification of markers of possible prognostic value in 57 giant cell tumors of bone. Oncol Rep 2003;10:351-6.
6. Wulling M, Engels C, Jesse N, Werner M, Delling G, Kaiser E. The nature of giant cell tumor of bone. J Cancer Res Clin Oncol 2001;127:467-74.

7. Kim HS, Lee JE, Jung SS, et al. Spinal cord injury due to the giant cell tumor of the second thoracic vertebra: a case report. Ann Rehabil Med 2013;37:269-73.

8. Sanjay BK, Sim FH, Unni KK, McLeod RA, Klassen RA. Giant-cell tumours of the spine. J Bone Joint Surg Br 1993;75:148-54.

9. Hart RA, Boriani S, Biagini R, Currier B, Weinstein JN. A system for surgical staging and management of spine tumors: a clinical outcome study of giant cell tumors of the spine. Spine (Phila Pa 1976) 1997;22: 1773-82.

10. Hunter CL, Pacione D, Hornyak M, Murali R. Giantcell tumors of the cervical spine: case report. Neurosurgery 2006;59:E1142-3.

11. Caudell JJ, Ballo MT, Zagars GK, et al. Radiotherapy in the management of giant cell tumor of bone. Int J Radiat Oncol Biol Phys 2003;57:158-65.

12. Feigenberg SJ, Marcus Jr RB, Zlotecki RA, Scarborough MT, Berrey BH, Enneking WF. Radiation therapy for giant cell tumors of bone. Clin Orthop Relat Res 2003;411:207-16.

13. Latchaw RE, Gold LH. Polyvinyl foam embolization of vascular and neoplastic lesions of the head, neck, and spine. Radiology 1979;131:669-79.

14. Finstein JL, Chin KR, Alvandi F, Lackman RD. Postembolization paralysis in a man with a thoracolumbar giant cell tumor. Clin Orthop Relat Res 2006; 453:335-40.

15. Hagiwara $Y$, Yonemoto T, Iwata S, Ishi T, Tatezaki S, Yamazaki M. Clinical evaluation of giant cell tumor of bone treating with embolization in trunk. Orthop Surg Traumatol 2011;54:1515-9.

16. Osaka S, Toriyama M, Taira K, Sano S, Saotome K. Analysis of giant cell tumor of bone with pulmonary metastases. Clin Orthop Relat Res 1997;(335):253-61.

17. Dominkus M, Ruggieri P, Bertoni F, et al. Histologically verified lung metastases in benign giant cell tumours: 14 cases from a single institution. Int Orthop 2006;30:499-504.

18. Thomas D, Henshaw R, Skubitz K, et al. Denosumab in patients with giant-cell tumour of bone: an openlabel, phase 2 study. Lancet Oncol 2010;11:275-80.

19. Chawla S, Henshaw R, Seeger L, et al. Safety and efficacy of denosumab for adults and skeletally mature 
adolescents with giant cell tumour of bone: interim analysis of an open-label, parallel-group, phase 2 study. Lancet Oncol 2013;14:901-8.

20. Aspenberg P. Denosumab and atypical femoral fractures. Acta Orthop 2014;85:1.

21. Khow KS, Yong TY. Atypical femoral fracture in a patient treated with denosumab. J Bone Miner Metab 2015;33:355-8.

22. Kobayashi E, Setsu N. Osteosclerosis induced by denosumab. Lancet 2015;385:539.

23. Luksanapruksa P, Buchowski JM, Singhatanadgige W, Rose PC, Bumpass DB. Management of spinal giant cell tumors. Spine J 2016;16:259-69.

24. Matcuk GR Jr, Patel DB, Schein AJ, White EA, Menendez LR. Giant cell tumor: rapid recurrence af- ter cessation of long-term denosumab therapy. Skeletal Radiol 2015;44:1027-31.

25. Wang CS, Lou JH, Liao JS, et al. Recurrence in giant cell tumour of bone: imaging features and risk factors. Radiol Med 2013;118:456-64.

26. Siddiqui MA, Seng C, Tan MH. Risk factors for recurrence of giant cell tumours of bone. J Orthop Surg (Hong Kong) 2014;22:108-10.

27. de Carvalho Cavalcante RA, Silva Marques RA, Santos VG, et al. Spondylectomy for giant cell tumor after denosumab therapy. Spine (Phila Pa 1976) 2016; 41:E178-82.

28. Goldschlager T, Dea N, Boyd M, et al. Giant cell tumors of the spine: has denosumab changed the treatment paradigm? J Neurosurg Spine 2015;22:526-33. 